\title{
A IMPORTÂNCIA DO MATERIAL DIDÁTICO NO ENSINO A DISTÂNCIA
}

\author{
LA IMPORTANCIA DEL MATERIAL DIDÁCTICO EN LA ENSEÑANZA A \\ DISTANCIA
}

THE IMPORTANCE OF DIDACTIC MATERIAL IN TEACHING AT DISTANCE

\author{
Bianca Cristina Michel ROSALIN ${ }^{1}$ \\ José Anderson SANTOS CRUZ ${ }^{2}$ \\ Michelle Beatriz Godoy de MATTOS $^{3}$
}

RESUMO: Este artigo tem por objetivo discutir a importância do material didático para o desenvolvimento dos cursos EaD (Educação a Distância ou Ensino a Distância), no entanto, optamos aqui como Ensino à Distância. É inegável que a educação Superior no Brasil deu um enorme salto nos últimos anos. Parte desse crescimento se deve à oferta do ensino à distância que, diante da flexibilidade de horários e da autonomia do aluno, tem despertado interesse cada vez maior no público estudantil, espalhados por diferentes faixas etárias. Nessa perspectiva, discute-se um pouco sobre o material didático utilizado na educação à distância, diretamente ligado ao processo de ensino e aprendizagem do aluno. Nesse sentido, evidenciar, através do exame de bibliografias sobre o tema, o valor dos materiais didáticos para fomento do ensino e da aprendizagem EaD. Concebidos a partir da filosofia da instituição de ensino, funcionam como uma espécie de cartão de visitas da instituição. Necessitam, por isso mesmo, passar por constante processo de avaliação, revisão e atualização para garantir a qualidade na ação educativa. O material didático utilizado - impresso ou virtual- é essencial, uma vez que expõe a organização, o desenvolvimento e o dinamismo do processo de ensino e aprendizagem. Identificar e caracterizar as ferramentas de aprendizagem $\mathrm{EaD}$, entre as diversas mídias disponíveis e os tipos de materiais didáticos pode ajudar a compreender o quanto são imprescindíveis na EaD.

Palavras-chave: Educação à distância. Material didático. Ensino e aprendizagem.

RESUMEN: Este artículo tiene por objetivo discutir la importancia del material didáctico para el desarrollo de los cursos EaD (Educación a Distancia o Enseñanza a Distancia), sin embargo, optamos aquí como Enseñanza a Distancia. Es innegable que la educación superior en Brasil ha dado un enorme salto en los últimos años. Parte de ese crecimiento se debe a la oferta de la enseñanza a distancia que, ante la flexibilidad de horarios y la autonomía del alumno, ha despertado interés cada vez mayor en el público estudiantil, esparcidos por diferentes edades. En esta perspectiva, se discute un

${ }^{1}$ Faculdade Anhanguera - Pólo Bauru. Coordenadora EaD.

${ }^{2}$ Faculdade Anhanguera de Bauru. Docente da Pós-graduação. Doutorando em Educação Escolar. Faculdade de Ciências e Letras, FCLar/Unesp. Bolsista CAPES. E-mail: joseandersonsantoscruz〉@gmail.com

${ }^{3}$ Faculdade Anhanguera de Bauru. Coordenadora da pós-graduação. E-mail: michelle.goody@anhanguera.com 
poco sobre el material didáctico utilizado en la educación a distancia, directamente ligado al proceso de enseñanza y aprendizaje del alumno. En este sentido, evidenciar, a través del examen de bibliografías sobre el tema, el valor de los materiales didácticos para el fomento de la enseñanza y del aprendizaje EaD. Diseñados a partir de la filosofía de la institución de enseñanza, funcionan como una especie de tarjeta de visita de la institución. Necesitan, por eso mismo, pasar por constante proceso de evaluación, revisión y actualización para garantizar la calidad en la acción educativa. El material didáctico utilizado - impreso o virtual- es esencial, ya que expone la organización, el desarrollo y el dinamismo del proceso de enseñanza y aprendizaje. Identificar y caracterizar las herramientas de aprendizaje EaD, entre los diversos medios disponibles y los tipos de materiales didácticos, puede ayudar a comprender lo imprescindibles en la EaD.

PALABRAS CLAVE: Educación a distancia. Material didáctico. Enseñanza y aprendizaje.

ABSTRACT: The purpose of this article is to discuss the importance of didactic material for the development of EaD (distance education or distance learning) courses, however, we chose here as Distance Learning. It is undeniable that Higher Education in Brazil has taken a huge leap in recent years. Part of this growth is due to the offer of distance education, which, given the flexibility of the hours and student autonomy, has attracted an increasing interest in the student public, spread over different age groups. From this perspective, we discuss a little about the didactic material used in distance education, directly linked to the student's teaching and learning process. In this sense, to highlight, through the examination of bibliographies on the theme, the value of didactic materials to promote teaching and learning EaD. Conceived from the philosophy of the educational institution, they function as a sort of business card of the institution. For this reason, they must undergo a constant process of evaluation, revision and updating to ensure quality in the educational action. The teaching material used - printed or virtual - is essential, since it exposes the organization, development and dynamism of the teaching and learning process. Identifying and characterizing EaD learning tools, between the various media available and the types of teaching materials can help to understand how much they are essential in EaD.

KEYWORDS: Distance education. Courseware. Teaching and learning.

\section{Introdução}

A crescente oferta de educação a distância no Brasil, depois de ter tomado impulso no mundo, não é mais nenhuma novidade. Cada vez mais, instituições de Ensino Superior se rendem às novas tecnologias de aprendizagem, ofertando EaD em um número cada vez maior de cursos de graduação e pós-graduação, esta última ainda desmembrada em especialização, aperfeiçoamento e cursos livres. É crescente, por 
conta disso, o índice de alunos matriculados na categoria e de professores e tutores, que desenvolvem os conteúdos e lançam mão de pesquisas para otimizar o setor. O cenário também flagra o aumento de publicações na área, principalmente no que tange às tecnologias disponíveis e aos materiais didáticos utilizados, visando autonomia e interatividade.

Ainda vista com certa desconfiança, a modalidade $\mathrm{EaD}$, além de legislação própria - que normatiza seu funcionamento e dá segurança aos alunos tal qual no modelo presencial, necessita garantir sua qualidade através do material didático oferecido, desafio muito maior do que no ensino tradicional, já que tem que ser pontual na interação do aluno com a plataforma, seus conteúdos e tarefas propostas. Impossível ficar alheio, em pleno século XXI, Era da Informação e da Comunicação, ao que a Internet nos proporciona em termos de aprendizagem. A criação de ambientes educativos virtuais, em uma interação on-line entre professores, alunos e tutores, possibilita interatividade simultânea ou em momentos diferentes, através do uso de outros recursos, como fóruns, e-mails, material impresso, etc.

A concepção de materiais didáticos para o ensino a distância é um processo que leva em conta a complexidade dos aspectos ligados ao ensino e aprendizagem porque exige a análise das informações científicas pelas quais se dá a construção do conhecimento, a concepção de educação da instituição e a gestão pedagógica e administrativa. Esses pontos são determinantes para a elaboração de material didático coeso com a filosofia adotada, o que vai muito além da seleção de conteúdo. A abordagem metodológica dos materiais para $\mathrm{EaD}$ deve ser adequada, proporcionando ao aluno direcionamentos para que possa explorar, com facilidade, todo o ambiente virtual. Dessa forma, o material didático oferecido deve enfatizar a reflexão, o desenvolvimento da autonomia e a construção do conhecimento. Necessita, sobretudo, de viabilizar a interação entre os alunos e alunos e professores. Precisa ser pensado e produzido, visando estimular o aluno a ser agente de seu próprio saber. $\mathrm{Na}$ atualidade, os cursos em EaD proporcionam ao aluno a possibilidade de autogerenciamento dos estudos, já que há liberdade de horário para estudar. Tempo e espaço são monitorados pelo próprio aluno, óbvio que com acompanhamento de um sistema de mediação pela Internet e avaliação sistemática de tarefas, atividades, participação em fóruns, etc.

O modelo EaD é regulamentado pelo Decreto-Lei no 2.494 de 10 de fevereiro de 1998. Além de graduação e pós-graduação, o modelo de ensino oferece cursos de extensão, aperfeiçoamento, especialização, técnicos, profissionalizantes, livres, entre 
outros. Averbug (2003) salienta que o acesso às Tecnologias da Informação e Comunicação, principalmente as inúmeras possibilidades proporcionadas pelos recursos da Internet, não devem deixar de lado o material impresso.

Ao traçarmos um breve histórico da Educação a Distância, no Brasil, podemos constatar a flagrante evolução: da correspondência ao virtual, um enorme e atrativo salto. No entanto, as novas Tecnologias da Comunicação e da Informação (TIC) podem conviver harmoniosamente com a oferta de material impresso e livros didáticos, complementando o processo de ensino e aprendizagem.

\section{Da tecnologia ao serviço da aprendizagem no EaD}

A Era da Informatização trouxe novas tecnologias nas áreas da informação e da comunicação, as chamadas TIC - Tecnologias de Informação e Comunicação, principalmente quando o assunto é Internet. Esta possibilitou a criação de espaços virtuais interativos de aprendizagem envolvendo professores, alunos e tutores, lançando mão de ferramentas como chats, videoconferências, fóruns, blogs, enquetes, exercícios, etc. Outros recursos, além do digital, estão disponíveis, como as já tradicionais videoaulas, material multimídia, audioaulas, jogos educativos, entre outras ferramentas, como as apostilas e livros; ressaltamos aqui, que nem toda população tem acesso a um computador conectado à rede.

Quanto a isso, soma-se o fato de que a inclusão digital vai muito além da posse de um computador ou outro dispositivo de acesso à internet - rede mundial de computadores. É preciso que os recursos disponíveis possam ser utilizados, de modo a gerar conhecimento. Segundo Larsen (1998), as novas mídias não são máquinas de ensinar, mas instrumentos que auxiliam na edificação do saber, a partir de outros já construídos. Completando esse raciocínio, Averbug (2003) salienta que estar munido das novas tecnologias exige novas posturas do professor/tutor diante do processo de ensino e aprendizagem, cabendo a estes o papel de mediadores do saber. Para o estudioso, os professores devem assumir, cada vez mais, o papel de coadjuvantes na construção do conhecimento do aluno. Essa diretriz transforma o mestre em mediador e incentivador, levando o aluno a protagonizar seus próprios saberes. Aos aprendizes cabe absorver o conhecimento, refletir sobre o mesmo e transformá-lo. 
Não há ensino sem pesquisa e pesquisa sem ensino. Esses que fazeres se encontram um no corpo do outro. Enquanto ensino contínuo buscando, reprocurando. Ensino porque busco, porque indaguei, porque indago e me indago. Pesquiso para constatar, constatando, intervenho intervindo educo e me educo. Pesquiso para conhecer o que ainda não conheço e comunicar ou anunciar a novidade (FREIRE,1987, p. 40).

Coloca-se em xeque, aqui, o uso de recursos como lousa, giz, livros e aulas expositivas, características do ensino dito tradicional. Muitas instituições EaD ainda dão guarida ao livro didático, juntamente com material apostilado, lembrando que, embora utilizado há séculos, também representou uma verdadeira revolução quando o alemão Gutenberg disseminou a aprendizagem em massa, através de sua invenção. Sancho (1998) avalia que o livro didático deve ser avaliado como uma ferramenta tecnológica também. Tanto do ponto de vista virtual, quanto do impresso, é certo que todo material deve ser concebido com responsabilidade, tendo-se claros os objetivos e concepções que os norteiam. Os conteúdos devem, a partir daí, ser criteriosamente selecionados, convidativos, desafiadores. Aretio (1994, p. 177) também acredita que o material didático em $\mathrm{EaD}$ tem a responsabilidade de "motivar, informar, esclarecer e programar o trabalho individual e em equipe".

Tanto o conteúdo da plataforma EaD quanto o material impresso, via portal ou recebido pelo Correio, deve levar o aluno a pesquisar em diferentes fontes, convidá-lo a saber mais a partir de indicações de leituras complementares, filmes, jogos, programas, sites, blogs, revistas, etc. Para Sales (2005), essa é uma possibilidade para o aluno ampliar seu conhecimento além do que está sendo tratado no texto. Bottentuit Junior e Coutinho (2008) acreditam que o material didático impresso é importante em EaD porque não depende de aparelhagens como computador, TV ou reprodutor de áudio, nem sempre acessíveis aos alunos. Aliás, voltando um pouco no tempo, podemos constatar que o ensino a distância não é algo inovador, já que passou pela fase da correspondência, do rádio, da televisão, até chegar ao mundo virtual com o advento da Internet.

Guarezi (2009) cita o pioneirismo do Instituto Universal Brasileiro. Ele lembra que a instituição, criada em 1941, fez uma avant-premier na modalidade EaD. "Primitivamente, por correspondência, utilizando, basicamente, material impresso". A instituição, hoje, plugada com as novas mídias digitais, oferece cursos EaD via Internet.

Nitzke, Gravina e Carneiro (2008), lembram que a segunda geração EaD veio 
com o uso do rádio e, posteriormente, da televisão, já na década de 50. A terceira geração foi concretizada através da junção das várias experiências, integrando o modelo de universidades abertas, com o uso de material impresso, transmissões via rádio e TV, além de kits para experiências práticas com os alunos, trazendo o feedback do modelo implantado.

\begin{abstract}
Na quarta geração, a tecnologia passa a permitir uma comunicação mais próxima entre professor/aluno e aluno/aluno. A teleconferência é vista como uma tecnologia significativa, tendo início com a audioconferência (transmissão somente de áudio, simultânea e multidirecional entre os participantes) e, depois, através da transmissão de áudio e vídeo (MOORE; KEARLEY, 2008, p. 45)
\end{abstract}

Nos dias atuais, podemos identificar uma quinta geração, com tecnologia avançada em um ambiente virtual de aprendizagem (AVA), que reúne ferramentas como e-mail, fórum, chats, listas de discussão, postagem de exercícios, tarefas e atividades, além de verificações de aprendizagem. As estratégias utilizadas e o material didático oferecido constituem o meio de comunicação entre os envolvidos no processo de ensino e aprendizagem. Devem ter fácil leitura, ser atrativos, desafiadores, já que estabelecem o processo comunicativo pelo qual se dará a engrenagem educativa. Velásquez (2009) salienta que é o material didático quem desempenha papel preponderante na constituição da informação e do conhecimento, uma vez que é ele o cartão de visitas, o contato entre o aluno e seu curso. "O material didático é o canal mais importante na comunicação com o aluno. Muitas vezes confunde-se até mesmo com o próprio curso" (AVERBUG, 2003, p. 9).

Em EaD, é o material didático quem faz a apresentação do aluno ao curso, o que exige uma esmerada produção em sua plataforma, que deve levar em conta a atratividade da primeira página, a facilidade na navegação, a objetividade, a interatividade nas tarefas e devolutivas pontuais. Neder e Prossari (2001 apud Santos, 2006) ressaltam que o material didático em $\mathrm{EaD}$ deve levar em conta os conhecimentos prévios dos alunos e indicar referências. Traçados os objetivos educacionais, deve estimular a autonomia e a participação do aluno na busca de novos conteúdos e aprendizados. Precisa desenvolver a relação tutor/aluno, aluno/tutor, aluno/aluno, através de um diálogo permanente entre os envolvidos.

As unidades de aprendizagem devem trazer diferentes abordagens metodológicas, como resolução de problemas, estudos de caso, reflexões sobre 
experiências, pesquisa, etc. $\mathrm{O}$ material didático também deve apostar na autonomia do aluno e no aumento de competências, tornando-o proativo na socialização de conhecimentos e no estabelecimento de diálogo para dar pareceres ou elucidar dúvidas. Por isso, precisa sugerir leituras complementares, pesquisas e tarefas que demandem interatividade com colegas e professores.

Os cursos $\mathrm{EaD}$ devem observar vários aspectos, desde a seleção de temas e conteúdos, até a adequação dos mesmos na plataforma virtual. O planejamento, rigoroso e detalhado, deve ocupar o lugar central. O material didático, juntamente com a concepção do canal midiático, deve atender aos objetivos, conteúdos, justificativas, contexto e perfil do público-alvo. Essa compatibilização é característica de um curso ímpar e o material didático é reflexo desta peculiaridade. É importante falar da avaliação e da autoavaliação do processo de ensino e aprendizagem dentro do ambiente virtual educacional. As avaliações do processo e as devolutivas do tutor possibilitam a autoavaliação do aluno. Parênteses para a importância da formação do tutor EaD para que este possa avaliar objetivamente o quanto o sistema implantado está sendo compreendido pelo corpo docente e pelos alunos.

Assim, é preciso ressaltar que os cursos a distância têm uma identidade própria porque possuem uma lógica administrativa e uma linguagem específica no que se refere à avaliação e aos recursos tecnopedagógicos que não simplesmente transposição do ensino presencial (BRASIL, 2003, p.6). Aretio (1994) afirma que o material didático deve contar com um professor-tutor ativo, que saiba motivar, dialogar, informar, esclarecer dúvidas, dar devolutivas precisas e pontuais, adaptar tarefas, levando-se em conta as peculiaridades de seus alunos, níveis, relacionar todas as experiências, orientar o trabalho individual e em equipe.

Auxiliar os alunos na compreensão dos serviços da instituição e sobre
a estrutura do curso e do programa; nortear os alunos sobre a
comunicação on-line adequada e as demandas da aprendizagem à
distância; promover atividades de socialização e estimular processos
cooperativos de aprendizagem; controlar a frequência e a participação
dos alunos e repassar à instituição as dificuldades que enfrenta junto
aos alunos devido a alguma falha do sistema; auxiliar na realização
das atividades propostas no conteúdo programático, identificando
pontos a serem a serem otimizados ou revistos (ARRIADA;
LANZARINO, 2008, p. 10-15)

É importante ressaltar, ainda, que a tutoria deve ser exercida por profissionais qualificados por uma formação mínima, com título de especialista na área afim do curso 
exercido. Dessa maneira, poderá auxiliar em questões ligadas ao conteúdo e contribuir no processo de construção coletiva do conhecimento. A instituição também pode criar e realizar um processo de seleção de tutores que deverão atuar nos cursos oferecidos, visando um melhor desempenho e dinamizar o modelo $\mathrm{EaD}$ com profissionais competentes e especializados. Os cursos EaD oferecem material impresso, audiovisual e multimídia. O material impresso pode ser composto por apostilas temáticas, elaboradas pela própria instituição, ou textos diversos adaptados, como artigos, reportagens, capítulos de livros, resenhas, entre outros, selecionados para aprofundar alguns temas. Os materiais audiovisuais também podem ser exclusivos da instituição, utilizados para ilustrar diferentes situações de aprendizagem, as teleaulas, por exemplo, ou vídeos instrucionais. Ou, ainda, filmes, documentários, telejornais, peças publicitárias, entre outros, adaptados aos temas propostos, buscando reflexão crítica e socialização da mesma.

O material multimídia engloba o texto escrito, o audiovisual e o gráfico, em CD-ROM ou pen-drives. Esse recurso sofisticado prevê animações, jogos interativos, vídeos, áudios, fotografias, gráficos, músicas, etc. Já o material on-line da plataforma virtual, plugada na rede mundial de computadores, além de todos os recursos multimídias possibilita acesso a diversos ambientes de aprendizagem, como portais, sites, blogs, etc. Com características que mudam conforme o suporte tecnológico utilizado, o material didático deve ser autoinstrutivo, isto é, ser um guia da aprendizagem, motivacional e fulgente a tal ponto que seu entendimento seja simples.

Como podemos observar, falar em material didático é também falar de mídias e ferramentas de aprendizagem. Em um ambiente virtual elas se misturam e se complementam. Isso porque há uma interdependência entre os suportes digitais, onde se dá o processo comunicativo professor-aluno, aluno-aluno, sem os quais não haveria como desenvolver materiais didáticos específicos. Assim, um livro ou uma apostila, ou qualquer outro tipo de material impresso constituem-se, ao mesmo tempo, em mídia, em ferramenta e material didático. É um suporte físico porque está impresso no papel. Já um texto que se acessado via Internet não existe como suporte físico, uma vez desligado o computador, ele deixa de existir. No entanto, pode ser impresso.

Bates (1995) lembra, com isso, que cada um desses meios de comunicação e ferramentas possuem uma linguagem específica, peculiar, uma forma diferenciada de apresentar e organizar o conteúdo. Para elucidar essa discussão, voltemos no tempo, mais especificamente no século II da Era Cristã. As cartas do apóstolo Paulo podem ser 
consideradas como pioneiras no ensino a distância. É óbvio que não existiam as palavras "mídias" ou "ferramentas" naquela época, mas, observando o que acontece hoje nos ambientes virtuais de aprendizagem, a definição EAD aplica-se a essa comunicação entre Paulo e seus seguidores espalhados no Império Romano. Depois, como já vimos, apareceram outras mídias revolucionárias, denominadas tecnologias por SCHEER (1999), mas que não têm valor, segundo Kearsley e Moore (1996), sem a intermediação humana.

De fato a educação à distância com todo o potencial das novas tecnologias da informação e da comunicação ainda é um objeto de aprendizado para nós, educadores. Ou seja, parodiando Umberto eco, é uma obra aberta, e como tal deve ser aprendida e enriquecida por cada um de nós. Com criatividade, conhecimento e competência, caminhos mais complexos podem ser trilhados. O pano de fundo do texto é minha crença na necessidade de democratizar a educação e na capacidade que temos todos nós, educadores, de fazer educação com elevado padrão de qualidade, independentemente de distâncias (NEVES, 2003, p.13).

A principal característica do material didático $\mathrm{EaD}$ é a de ser uma verdadeira bússola para o aluno, um guia que, além de indicar caminhos, motive-o, avalie-o e propicie uma autoavaliação. Para que os objetivos didáticos sejam alcançados, é necessário elaborar um material didático que

Enfrente a realidade concreta do ensino; enfrente as próprias limitações pedagógicas; descobrir o valor extraordinário da clareza como pressuposto, mais que didático ético da linguagem; localizar com mais nitidez as relevâncias e as irrelevâncias do processo de aprendizagem; atualizar conteúdos; e, talvez o mais importante, a preparação de um material que é em si um modo objetivo de prestar atenção em quem nos ouve, não por democratismo demagógico, mas para saber de fato para quem estamos falando (TEZZA, 2002, p. 35$42)$.

Os Referenciais de Qualidade para a Educação Superior a Distância - RQESD (BRASIL, 2007) preveem a concepção de um material didático que possua propriedades singulares, diferenciadas daquelas utilizadas nos cursos presenciais. Deve sustentar-se na criatividade, no dinamismo, na interatividade, na autonomia e na autorresponsabilização do processo de aprendizagem, fazendo da educação a distância uma modalidade com identidade própria. Essa personalidade EaD é constituída pela legislação que a sustenta e pelo material didático que oferta. A apresentação do material 
deve ser de qualidade, expressado por aparência impecável e motivadora. Deve amparar, nas entrelinhas, a filosofia da instituição, através da elaboração de conteúdos convidativos, claros, trazerem referências bibliográficas instigantes e aguçar o espírito de pesquisa.

A sedução é a palavra-chave do material didático que, para Rondelli (2007), demanda a elaboração de uma equipe com magnífica formação acadêmica e cultural. Segundo os RQESD, o material didático quanto à forma e conteúdo deve ser elaborado a partir dos princípios epistemológicos, metodológicos e políticos explicitados no projeto pedagógico da instituição, o que constitui sua filosofia educacional. Dessa forma, busca-se facilitar a construção do conhecimento e mediar a interlocução entre estudante e professor, devendo passar por rigoroso processo de avaliação prévia, com o objetivo de identificar necessidades de ajustes, visando ao seu aperfeiçoamento. Embora não tenham força de lei, os Referenciais são norteadores para auxiliar o poder público na supervisão, avaliação e regulação dos cursos EaD.

Os Referenciais de Qualidade apontam para as concepções teóricometodológicas da educação a distância. É oportuno ressaltar que não há um modelo único de $\mathrm{EaD}$, cada um se utiliza de metodologias e tecnologias específicas para atender seu público-alvo e os cursos oferecidos. Para que o aluno não se sinta isolado no processo de ensino e aprendizagem em ambiente $\mathrm{EaD}$, é importante que a plataforma virtual incentive a interatividade e a colaboração. Assim, mesmo estando "só", o aluno poderá trabalhar colaborativamente, uma vez que

A vida começa apenas no momento em que uma enunciação encontra outra, isto é, quando começa a interação verbal, mesmo que não seja direta, de pessoa a pessoa, mas mediada pela literatura (BAKHTIN, 2006, p. 13).

Piva (2011), ratificando Bakhtin, afirma que o conhecimento nasce da interação entre o sujeito, o objeto, o material didático, o tutor e os demais alunos. Por isso mesmo, Catapan (2010) acredita que a preparação de um material didático de qualidade deve levar à compreensão crítica da situação e do contexto social, político e cultural, estimulando a reflexão sobre o meio em que vive e a transformação da realidade, reconstruindo um conhecimento já elaborado pela humanidade, mas que ganha roupagem nova a partir da internalização pessoal na construção do conhecimento. A 
necessidade de reavaliação constante do material didático $\mathrm{EaD}$ "promove uma 'educação sem distância', na qual todos aprendem e ensinam” (SILVA, 2011, p. 35).

Aliás, aprender a aprender é o grande mote EaD. A autonomia,

É produto de um processo interativo definido pela essência interdependente de cada indivíduo como ser social que é. Deve-se reconhecer que a autonomia do aprendiz é muito mais um produto da interdependência do que da independência. Sendo assim, os aprendizes devem ser ajudados a adquirir autonomia por meio de um processo de interação semelhante à aprendizagem formal (WISSMANN, 2006, p. 3).

A autonomia e a independência também devem favorecer as inter-relações, capacidade do indivíduo do século XXI em interagir com seus pares colaborativamente. Embora aparentemente antagônicas, os conceitos de autonomia/independência e interatividade são complementares e capitais para o ensino e a aprendizagem EAD. Como estratégia, o estímulo à interação e interatividade deve proporcionar a cooperação entre os alunos, propiciando a formação de grupos de estudos e comunidades de aprendizagem.

Todos que vão elaborar cursos nas redes digitais devem ter consciência que professores e alunos são seres sociais e que aprendem melhor em um sistema cooperativo, baseado em trocas de informação e opiniões e no trabalho coletivo. Nessa forma mais avançada de ensino interativo, mediado pelas tecnologias digitais, a participação de todos é indispensável (WISSMANN, 2006, p. 3).

Segundo Mattar (2011), resultados de pesquisas dos últimos anos, no Brasil e no mundo, apontam para uma otimização dos portais de ensino a distância, uma vez que estes, através de seus sistemas de acompanhamento didático - via fórum, postagens, entrega de tarefas, entre outras formas de avaliação - conseguem monitorar a aprendizagem dos alunos. A participação síncrona, as devolutivas e as notas ampliam a sensação de interconectividade, não mais restrita a uma sala de aula com dia e horários marcados. $\mathrm{O}$ acesso à aprendizagem se faz por meio do tablete, computador, celular e notebooks, assim,

A escola precisa entender que parte da aprendizagem pode ser feita sem estarmos na sala de aula e sem a supervisão direta do professor. Isso assusta, mas é um processo inevitável (MORAN, 2012, p. 69) 
Quanto a isso, Wissmann (2006) destaca que essa pretensa autonomia necessita de um caminhar independente, de uma demanda de interatividade, já que o sujeito é um ser social. É exatamente nessa perspectiva que caminham os estudos de Kenski (2009), já que enfatiza o caráter social de professores e alunos. A essência social promove um aprendizado melhor, mais dinâmico, alavancado pelos princípios da cooperação e intercâmbio de informações e opiniões. Martins e Oliveira (2008, p.8) afirmam que é no material didático de qualidade e no design da plataforma que surge a "voz do professor". "O material didático é um recurso de comunicação pedagógica".

O trabalho coletivo, aqui, se faz em uma avançada plataforma de interatividade, intercedido pelas tecnologias digitais, onde a participação de todos é indispensável (KENSKI, 2009, p.124-125).

\section{Considerações finais}

Partindo da análise de bibliografia sobre a importância do material didático EAD, ficou evidenciado que eles cumprem papel fundamental na sustentação dos cursos bancados pela instituição nessa modalidade. Com formatos variados, constituem espécie de chamariz para o aluno, que será ou não seduzido pela organização do conteúdo e dinamismo do processo educativo. A qualidade desse material depende de planejamento, desenvolvimento e aplicação, voltando sempre à reflexão crítica e reavaliação dos conteúdos, a partir da avaliação e da autoavaliação dos alunos. Longe de ser estanque, a modalidade EaD deve manter os níveis de qualidade a fim de acabar, de vez, com a desconfiança que a modalidade ainda exerce sobre muitas pessoas.

No material didático se concentra a proposta do curso, sua base e orientação pedagógica, o papel dos tutores e dos alunos (BORGES; JESUS; FONSECA (2012). Diante do exposto, fica claro que o material didático $\mathrm{EaD}$ deve mediar a relação do aluno com seu processo de ensino e aprendizagem, ao que Martins e Oliveira (2008) definem como ser a "voz do professor", seu clamor, mesmo que virtualmente. Materiais didáticos impressos e os ambientes virtuais de aprendizagem são ferramentas comunicativas e pedagógicas relevantes na atuação do $\mathrm{EaD}$.

Segundo Porto (2006), a comunicação é essencial no processo educacional. Nela, alunos e professores constituem uma analogia em que ensinar é também aprender e vice-e-versa. Nesse pressuposto, a avaliação é essencial para a revisão do material e de 
toda a plataforma $\mathrm{EaD}$, incluindo-se, aí, tanto o material impresso quantos os conteúdos virtuais.

“Os programas de ensino à distância, pelo seu caráter diferenciado e pelos desafios que enfrentam, devem ser acompanhados e avaliados em todos os seus aspectos, de forma sistemática, contínua e abrangente”. (NEVES, 2003, p. 9)

Modalidade de ensino de cunho social, continuada e organizada, contribui com o direito básico de "aprender", pois uma de suas características é a possibilidade de ultrapassar barreiras geográficas e temporais. Ultimamente, a crescente demanda por educação continuada é fator que aponta para a expansão da EaD no Brasil. Os integrantes envolvidos em programas de educação a distância devem ter experiência na área ou receber treinamento específico para exercer essa tarefa, tão desafiadora quanto gratificante. $\mathrm{O}$ uso da rede global de computadores como ferramenta de ensino exigiu a criação de materiais didáticos multimídia, interativos, criativos e sedutores, já que estes constituem, via de regra, o cartão de apresentação para o aluno (BRASIL, 2007b, p.7).

No que se refere à avaliação é ela quem "certifica a seriedade da instituição, estabelece a credibilidade e sustenta os parâmetros de aprendizagem, os objetivos de ensino e a sustentabilidade do projeto" (BITTENCOURT, 2010, p.91).

Bittencourt (2010) ainda afirma que a avaliação deve ser contínua, sistemática, planejada e abarcar todos os envolvidos no processo de ensino e aprendizagem, lembrando que a procura pelos cursos superiores de graduação e pós-graduação no sistema EaD cresce a cada ano. Segundo Carlos Longo, diretor da Associação Brasileira de Ensino a Distância (ABED), "a tendência é o número de alunos dobrar nos próximos cinco anos". O EaD no Brasil fechou 2013 com 1,2 milhão de alunos matriculados, enquanto o sistema total registrou sete milhões, segundo dados do Censo da Educação Superior. Isso mostra que a educação a distância tem conquistado a confiança do alunado, que procura por cursos superiores de bacharelado, licenciatura, tecnológicos, pós-graduação, especialização e aperfeiçoamentos.

Essa confiança pode ser traduzida em políticas governamentais de fomento à área, à realidade de uma sala de aula virtual, interativa e dinâmica entre tutor/aluno, aluno/tutor e aluno/aluno e à confecção de material didático adequado, que prime pela qualidade, com conteúdos objetivos, claros e interativos, respeitando as características do curso e de seu público-alvo. Assim, como dizia Richard Bach, autor do célebre Fernão Capello Gaivota, “aprender é descobrir aquilo que já se sabe. Fazer é 
demonstrar o que você sabe. Ensinar é lembrar aos outros que eles sabem tanto quanto você. " E essa pretende ser a maior filosofia EaD no país.

\section{AGRADECIMENTOS: CAPES}

\section{REFERÊNCIAS}

ALVES, L. Educação à distância: conceitos e história no Brasil e no mundo. Revista Brasileira de Aprendizagem Aberta e a Distância, São Paulo, v. 10, p. 83-92, 2011.

ARETIO, L. G. Educacion a distancia hoy. Madri: Universidad Nacional de Educacion a Distância (UNED), 1994.

ASSOCIAÇÃO BRASILEIRA DE EDUCAÇÃO A DISTÂNCIA (ABED). Censo EAD.BR: relatório analítico da aprendizagem a distância no Brasil. São Paulo: ABED/FGV online/UNINTER, 2013. Disponível em: <http://www.abed.org.br/censoead2013/CENSO_EAD_2013_PORTUGUES.pdf>. Acesso em: 01 fev. 2016.

AVERBUG, R. Material didático impresso para a educação à distância: tecendo um novo olhar. Colabor@ - Revista Digital da Comunidade Virtual de Aprendizagem Rede de Instituições Católicas de Ensino Superior, Santos, v. 2, n. 5, p. 16-31, 30 jan. 2015.

BAKHTIN, M. Estética da criação verbal. Trad. Maria Ermantina Galvão G. Pereira. São Paulo: Martins Fontes, 1997.

BAKHTIN, M. Marxismo e filosofia da linguagem. Trad. Michel Lahud. São Paulo: Hucitec, 2006.

BAUMAN, Z. Modernidade líquida. Trad. Plínio Dentzien. Rio de Janeiro: Zahar, 2001.

Revista da FAEEBA. Educação e contemporaneidade, Salvador, v. 23, n. 42, p. 119 130, dez. 2014

BERNARDO, V. Educação a Distância: fundamentos e guia metodológico, São Paulo: UNIFESP Virtual. Disponível em:

<http://www.virtual.epm.br/material/tis/enf/apostila.htm>. Acesso em: 18 fev. 2016.

BORGES, E. M.; JESUS, D. P.; FONSECA, O. F. Material didático em educação à distância: fragmentação da docência ou autoria. GUAL, Florianópolis, v. 5, n. 4, p. 141-152, 2012. 
BOTTENTUIT JUNIOR, J. B.; COUTINHO, C. M. P. As ferramentas da Web 2.0 no apoio à tutoria na Formação em E-learning. In: Association francophone internationale de recherche scientifique en education, 2008, Lisboa. Tutoria e mediação em educação: Novos desafios à investigação educacional. Anais...Lisboa: Association Francophone Internationale de Recherche Scientifique em Education, 2008. Disponível em: <http://repositorium.sdum.uminho.pt/bitstream/1822/7767/1/Afirse\%25202008.pdf>. Acesso em: 17 jan. 2016.

BRASIL. Ministério da Educação. Referenciais de qualidade para educação superior à distância. Brasília, 2003. Disponível em:

<http://portal.mec.gov.br/seed/arquivos/pdf/ReferenciaisdeEAD.pdf >. Acesso em: 10 jan. 2016

CATAPAN, A. H. al. Uma metodologia para elaboração de material didático para EAD. Florianópolis, 2010. Disponível em:

<http://www.abed.org.br/congresso2010/cd/252010230351.pdf>. Acesso em: 20 fev. 2016.

CORREAA, M. A. Os Materiais didáticos como recursos fundamentais de potencialização da qualidade do ensino e aprendizagem na EAD. E-Tech: Tecnologias para Competitividade Industrial, Florianópolis, v. 6, n. 1, p.125-140, 2013.

COSTA JUNIOR, I.; CAMPOS, F. Desafios da Educação a Distância: pressupostos para reflexão. In: Congresso Brasileiro de Ensino Superior a Distância, 5, 2008, Porto Alegre. Anais...Porto Alegre: Congresso Brasileiro de Ensino Superior a Distância, 2008. v. 1.

ECO, U. Lector in fabula. Trad. Attílio Cancian. São Paulo: Perspectiva, 1985.

FREITAS, K. S. Um panorama geral sobre a história do ensino à distância. Educação à distância no contexto brasileiro: algumas experiências da UFBA, v. 1, Salvador, p. 57-68, 2005. Disponível em: <http://www.proged.ufba.br/ead/EAD\%205768.pdf> Acesso em: 18 jan. 2016.

HATOUM, M. Por que traduzi Flaubert. 2012. Disponível em: <http://www.miltonhatoum.com.br/do-autor/traducoes-do-autor/por-que-traduziflaubert>. Acesso em: 30 jan. 2016.

KENSKI, V. M. Tecnologias e ensino presencial a distância. 7. ed. Campinas, SP: Papirus, 2009.

LARSEN, S. New technologies in education: social and psychological aspects. In: LOVIS, T.; TAGG, E. D. (eds.), Computers in education. Proceedings of the IFIP TC3. Amsterdam: Elsevier Science Publisher, 1988.

LÉVY, P. Cibercultura. São Paulo: ed. 34, 1999.

MARTINS, J. G.; OLIVEIRA, N. F. de. Material didático: desconstruindo o ontem para construir o hoje e o amanhã. [S.l: s.n.], 2008. Disponível em: $\langle$ http://www.abed.org.br/congresso2008/tc/512200834611PM.pdf > . Acesso em: $30 \mathrm{dez}$. 2016. 
MATTAR, J. Tutoria e interação em educação a distância. São Paulo: Cengage Learning, 2011.

MOORE, M. G.; KEARSLEY, G. Educação à distância: uma visão integrada - Edição especial ABED - Associação Brasileira de Educação a Distância. São Paulo: Thomson Learning, 2007. 139. E-Tech: Tecnologias para Competitividade Industrial, Florianópolis, v. 6, n. 1, p.125-140, 2013.

MORAN, J. M. Tablets para todos conseguirão mudar a escola? Disponível em: <http://moran10.blogspot.com.br/search/label/novas\%20tecnologias>. Acesso em 25 jan. 2016.

NEVES, C. M. de C. Indicadores de qualidade para cursos à distância. Brasília, 2003. Disponível em: <http://www.pr5.ufrj.br/curso_distancia/legislacao/ Indicadores_de_Qualidade_do_MEC.pdf>. Acesso em: 27 dez. 2015.

OITICICA, H. Aspiro ao grande labirinto. Rio de Janeiro: Rocco, 1986.

POMMER, A.; SILVA, E. W. da et al. Educação superior na modalidade à

distância: construindo novas relações professor-aluno. Série Textos Didáticos. Ijuí/RS: Editora Unijuí, 2006. Disponível em: <http://www2.unijui.edu.br/ liaw/Autonomia\%20 em\%20EaD\%20.pdf>. Acesso em: 06 dez. 2016.

PORTO, Tânia Maria Esperon. As tecnologias de comunicação e informação na escola: relações possíveis...relações construídas. Rev. Bras. Edu [online], v. 11, n.31, p.43- 57, jan./abr. 2006. Disponível em:

<http://www.scielo.br/scielo.php?script=sci_arttext\&pid=S1413-24782006000100005>. Acesso em: 09 dez. 2015.

SALES, M. V. S. Uma reflexão sobre a produção do material didático. In: Congresso Internacional de Educação a Distância, 12, 2005, Florianópolis. Anais... São Paulo: Associação Brasileira de Educação a Distância, 2005. Disponível em: <http://www.abed.org.br/congresso2005/por/pdf/044tcf5.pdf> Acesso em: 18 jul. 2012.

SANCHO, J. M. Para uma tecnologia educacional. Porto Alegre: ArtMed,1998. SARTORI, A. S.; ROESLER, J. Educação superior à distância: gestão da aprendizagem e da produção de materiais didáticos impressos e on-line. Tubarão: Unisul, 2005.

CHEER, S. Multimeios em EaD. In: MARTINS, O. B. Educação a distância: um debate multidisciplinar. Curitiba: UFPR, 1999. p. 159 - 175.

SILVA, C. N. N.; CARNIELLI, B. L. Educação superior a distância no contexto da política de formação de professores. Revista da UFG, v. 7, n. 2, dez., 2005. Disponível em: <http://www.proec.ufg.br/revista_ufg/45anos/I-EAD.html>. Acesso em: $18 \mathrm{dez}$. 2015 .

TEZZA, C. Material didático - um depoimento. Educar em Revista, Curitiba, n. 20, p. 35-42, 2002. Disponível em: 
<http://www.cristovaotezza.com.br/textos/palestras/p_materialdidatico.htm>. Acesso em: 10 dez. 2015.

TORRES, P. L.; FIALHO, F. A. P. Educação à distância: passado, presente e futuro. In: LITTO, F. M.; FORMIGA, M. M. M. (Orgs.). Educação a distância: o estado da arte. São Paulo: Pearson Education do Brasil, 2009.

VELASQUEZ, F. da S. Materiais didáticos na educação a distância. Disponível em: <http://www.seednet.mec.gov.br/artigos.php?codmateria=1502>. Acesso em: 13 fev. 2016

\section{Como referenciar este artigo}

ROSALIN, Bianca Cristina Michel.; SANTOS CRUZ, José Anderson.; MATTOS, Michelle Beatriz Godoy de. A importância do material didático no ensino a distância. Revista on line de Política e Gestão Educacional, Araraquara, v. 21, n. esp. 1, p. 814830 , out./2017.

Submetido em: 10/04/2017

Aprovado em: 20/09/2017 